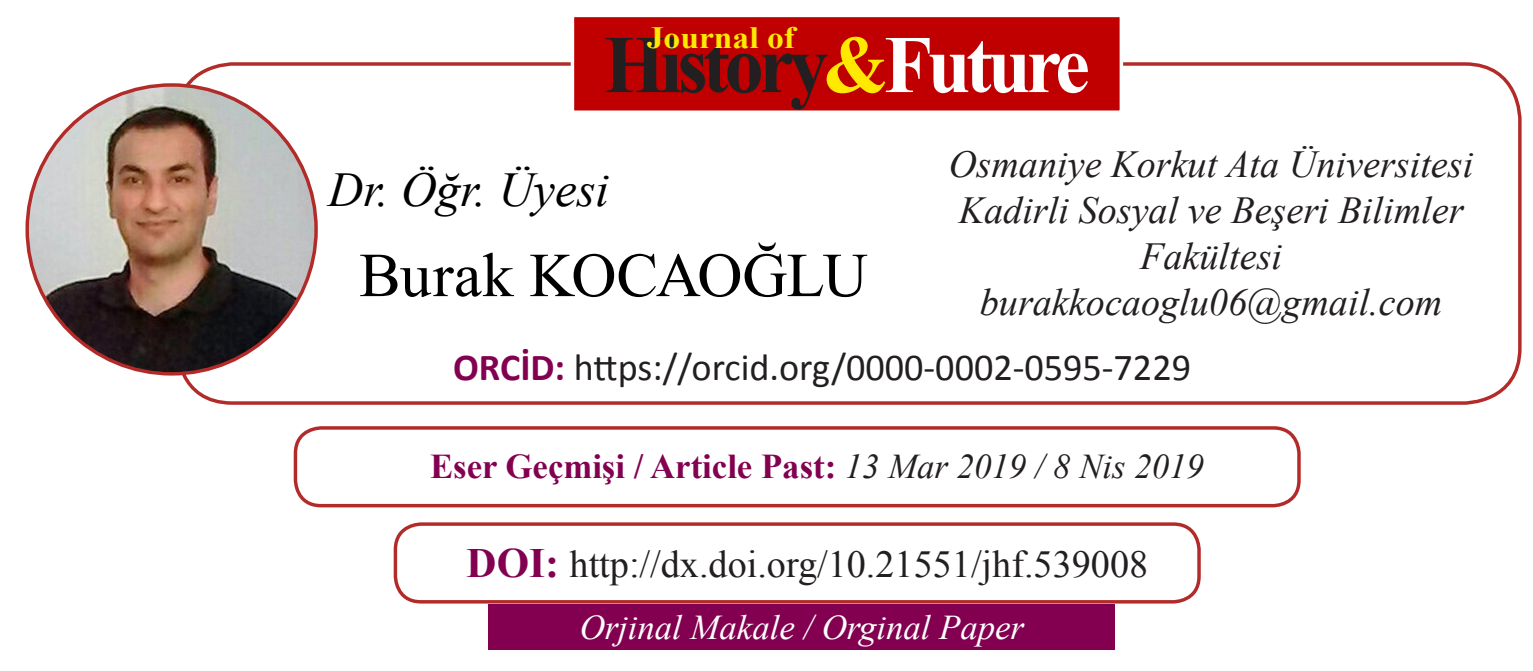

\title{
Osmanlı Donanması'nın Tatlı Su İhtiyacının Karşılanması
}

\author{
The Needs Of Fresh Water Ottoman Navy
}

\section{Öz}

Askeri operasyonların başarıya ulaşmasında ve ülkenin korunmasında, muharip güçlerin teknik donanımı, talim ve disiplinlerinin yanı sıra, sefer öncesi ve sonrası yapılan hazırlıklarda önemli rol oynamıştır. Günümüzde lojistik olarak adlandırılan, sefer öncesi ve sefer sırasında yürütülen bu faaliyetler Osmanlı askeri tarihi literatüründe iaşe ve ikmal olarak geçmektedir. Bu konuları ele alan çalışmalarda iaşe ve ikmal malzemelerinin neler olduğu, hangi yollarla temin edildiği gibi sorular genellikle cevapsız bırakılmıştır. Osmanlı askeri için en önemli ihtiyaç maddelerinin başında su gelmektedir. Su, insan ve doğadaki her canlının yaşam kaynağıdır. Bu sebepten Osmanlı Devleti gerek kara gerekse deniz kuvvetlerinin su temini konusuna büyük önem vermiştir. Nispeten kara ordusunun su ihtiyacının karşılanması kolay olup, ordunun ilerleyeceği güzergâh boyunca nehir ve göl gibi tatlı su kaynaklarından ve önceden içleri kar doldurulan kuyularından, kara ordusunun su ihtiyacı rahatlıkla karşılanabilmiştir. Ancak uzun süre seyrüsefer halinde olan ve limana yanaşma şansı olmayan donanmaya ait gemiler için bu kolaylıktan söz edilemez. Bunun içindir ki devlet, donanmaya ait gemilerin su ihtiyacının karşılanması için iç hacmi büyük, mancana, fiçı ve varil gibi su bidonlarını imal edip gemilere yüklemiştir. Bu çalışmada 18. yüzyılın son çeyreğinden 19. yüzyılın ilk çeyreğine, Osmanlı donanmasının ihtiyacı olan su bidonlarının imalatı için gerekli olan malzemelerin neler olduğu, bunların hangi yollardan ve nerelerden temin edildiği, hangi vasıtalarla nerelere nakledildiği ve üretimin nasıl gerçekleştiği arşiv belgelerine dayalı olarak ele alınmıştır.

Anahtar Kelimeler: Su, Tahta, Mancana, Gemi, Kalyon. 


\begin{abstract}
The protection of the country and success of military operations, the combatant forces, the technical equipment, training and discipline, as well as, pre and post preparation play important role. Todays, logistics, called in the military history litearature the activities, that are executed during the time before and the time is Ottoman food and supply. İssues often addressed superficially ratioing and supply of the Ottoman army sea has been, what materials, with wihc such questions are often left unanswered that it has been supplied. If, we were to ask what is most important in this pahase will be the answer water. Water is the source of all living things and in human and nature. Fort his reason, the need to land and naval forces of the Ottoman Empire, great importance is water supply. Relatively easy to meet the water needs of land army, sources of fresh water such as rivers and lakes and snow borehole along the route of advance form, the need for water can be met easily. However, it cannot be that easy naval force, the navigation and brething harbour for a long time. In this state, the navy ship to meet the water needs of the interior volume is large, such as, demijohn, kegs, and barrels loaded water. In this study, what we need before the manufacturing stage of these water bins, what means and where they are obtained from, what means of supply of the material used to be transported, where the production is carried out, based on the archive documents from the last quarter of the 18th century to the first quarter of the 19th century when taking time We will try to show.
\end{abstract}

Keywords: Water, Wood, Demijohn, Ship, Galleon.

\title{
Giriş
}

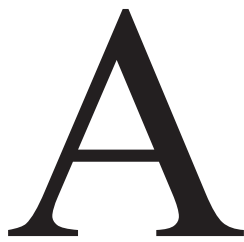

skeri operasyonların başarıya ulaşmasında ve ülkenin korunmasında, muharip güçlerin teknik donanımı, talim ve disiplinlerinin yanı sıra, sefer öncesi ve sonrası yapılan hazırlıklar da önemli rol oynamıştır. Günümüze kıyasla kullanılan vasitalarının son derece ilkel ve tamamen insan ve hayvan gücüne dayalı yürütüldügü devirlerde bu tür hazırlıklar daha da ehemmiyet kazanmıştır. Günümüzde lojistik olarak adlandırılan, sefer öncesi ve sefer sırasında yürütülen bu faaliyetler Osmanlı askeri tarihi literatüründe iaşe ve ikmal olarak geçmektedir. ${ }^{1}$ İaşe ve ikmal meselesi savaşın sonucunu direkt etkileyen konulardır. Bu nedenle dönemin önemli kara ve deniz kuvvetlerinden bir tanesine sahip olan Osmanlı Devleti ${ }^{2}$ ordunun iaşesi ve ikmaline büyük önem vermiştir. ${ }^{3}$ Batıl1 ve yerli kaynaklarda belirtildiği üzere Osmanlı askerleri, yükselme döneminde ${ }^{4}$ herhangi bir başka

1 Ömer İşbilir, "Osmanlı Ordularının İaşe ve İkmali: I. Ahmed Devri İran Seferleri Örneğì", Türkler, C.10, (Edt. Hasan Celal Güzel) Yeni Türkiye Yayınları, Ankara 2002, s.278.

2 Gabor Agoston, Osmanlı'da Strateji ve Askerî Güç, (Çev. M. Fatih Çalışır) Timaş Yayınları, İstanbul, 2015, s. 246-247

3 Gültekin Yıldız, "Kara Kuvvetleri”, Osmanlı Askeri Tarihi Kara, Deniz ve Hava Kuvvetleri 1792-1918, (Edt. Gültekin Yıldız), Timaş Yayınları, İstanbul, 2017, s. 65.

4 Sokullu Mehmed Paşa'nın Kaptan-1 Derya olan Kılıç Ali Paşa'ya söylemiş olduğu, istersek biz tüm donanmanın lengerlerini gümüşten yelkenlerini atlastan yaparız sözü Osmanlı Devleti'nin o zamanki güç ve kudretini göstermesi açısından oldukça önemlidir. İ.Hakkı Uzunçarşı1l, Osmanlı Devleti'nin Merkez ve Bahriye Teşkilâtı, T.T.K., Ankara, 1988, s. 446. 
Avrupa Devletinin ordusundan daha iyi ikmal koşullarına sahip ${ }^{5}$ olmamasına karşın duraklama ve çöküş dönemlerinde ${ }^{6}$ bu durumdan tam olarak söz etmemiz pek mümkün olmasa da, devlet yinede kendi kendine yetebilecek seviyesini ${ }^{7}$ uzunca bir süre muhafaza edebilmiştir. ${ }^{8}$ Şüphesiz bunda devletin, ordu için gerekli olan malzemeleri kendi geniş sınırları içerisinden kolaylıkla temin etmesi ${ }^{9}$ etkili olmuştur.

Osmanlı ordusunun iaşe ve ikmal malzemelerinin listesini yazmamız için yüzlerce maddeyi bir araya getirmemiz gerekecektir. Ancak bu maddeler içerisinde şüphesiz en önemlisi su olacaktır. $\mathrm{Su}$, insan ve doğadaki her canlının yaşam kaynağı olup belirli bir süre susuz kalmak hayati fonksiyonların yavaşlamasına ve ölüme neden olacaktır. Bu sebepten Osmanlı Devleti gerek kara gerekse deniz kuvvetlerinin su temini konusuna büyük önem vermiştir. Nispeten kara ordusunun su ihtiyacının karşılanması kolay olup, ordunun ilerleyeceği güzergâh boyunca yer alan menzillerden ${ }^{10}$, nehir ve göl gibi tatlı su kaynaklarından ve önceden içi kar doldurulan kuyularından, kara ordusunun su ihtiyacı rahatlıkla karşılanabilmiştir. Ancak uzun süre seyrüsefer halinde olan ve limana yanaşma şansı olmayan donanmaya ait gemiler için bu kolaylıktan söz edilmesi mümkün olmamıştır. Bunun içindir ki devlet, donanmaya ait gemilerin su ihtiyacının karşılanması için iç hacmi büyük, çeşitli türden su bidonlarını gemilere yüklemiştir. Mancana ${ }^{11}$, varil ve fıçı adı verilen tahtadan yapılmış ve demirle güçlendirilmiş olan bu su kaplar1 ${ }^{12}$ sayesinde gemi içerisinde bulunan ordunun çeşitli sınıflarına mensup askerler uzunca bir süre karaya çıkmadan temiz su ihtiyaçlarını karşılayabilmiş ve seyrüsefer devamlılığı sağlıklı bir şekilde sağlanmıştır.

\section{Malzeme Temini}

Donanmaya ait gemilerde bulunan askerlerin su ihtiyacının giderilmesi için gerekli olan çeşitli boyutta mancana, varil, fiçı ve gerdelin inşası için yoğun olarak fiçı tahtası gerekmiştir. Gerekli olan tür ve uzunlukta fiçı tahtasının İstanbul' da bulunan varilci esnafından temini mümkün olmasa da $^{13}$ çoğunlukla devletin sınırları içerisinden gerekli olan tahta temin edilmişstir. Tahtaların temin edildiği yerlere bakacak olursak karşımıza ilk olarak Eflak ve Boğdan voyvodalıkları çıkmaktadır. Voyodalardan talep edilen miktar genellikle senelik 50.000 fiçı tahtası ${ }^{14}$ üzerinden olmuştur. Ancak

5 Kenneth Chase, Ateşli Silahlar Tarihi, (Çev. Füsun Tayanç), Türkiye İş Bankası Kültür Yayınları, İstanbul, 2008 , s.111.

6 Virgina. H.Aksan, Kuşatılmış Bir İmparatorluk Osmanlı Harpleri 1700-1870, (Çev. Gül Çağalı Güven), Türkiye İş Bankası Kültür Yayınları, İstanbul, 2011, s.156-157.

7 Suraiya Faroqhi “İktisat Tarihi”, Türkiye Tarihi, C.2, (Yay. Yön. Sina Akşin) Cem Yayınları, İstanbul 1997, s. 176.

8 Osmanlı Devleti'nde askeri harcamaların ve sefer hazırlıklarının bütçeye etkisini görmek için bknz. Ahmet Tabakoğlu, Osmanlı Mali Tarihi, Dergah Yayınları, İstanbul, 2016.

9 Gabor Agoston, Osmanlı’da Ateşli Silahlar ve Askeri Devrim Tartışmaları, (Yay. Haz. Kahraman Şakul), İş Kültür Yayınları, İstanbul, 2017, s. 59-60.

10 Aleksandır Antonov, "Bulgar Topraklarında Kurulan Menzil Sisteminin Organizasyonu (XVI-XVIII. Yüzylllar)”, Türkler, C.10, (Edt. Hasan Celal Güzel), Yeni Türkiye Yayınları, Ankara 2002, s.1719.

11 Damacana denilen su kabının eski adıdır. Mehmet Zeki Pakalın, “Mancana”, Osmanlı Tarih ve Deyimler Sözlüğü, C.2, Milli Eğitim Basımevi, İstanbul, 1983, s.404.

12 İdris Bostan, Osmanlı Bahriye Teşkilâtı: XVII. Yüzyılda Tersâne-i Âmire, T.T.K., Ankara, 2003, s.77.

13 BOA. C.BH.265-12234., H.1198 (M.1784) tarihli belgede, donanma kalyonlarına verilecek olan su mancalarının hazırlanmas1 için 7 karışlık 21.000 tahtaya ihtiyaç olup, bu tahtaların İstanbul'da varilci esnafının elinde olmadığı ancak Ahtapolu'da 20.000'den fazla tahtanın olduğu bildirilmiştir.

14 BOA. C.BH.271-12501., H.1216 (M.1801) tarihli belgede, Eflak bölgesinden donanma kalyonlarında kullanılacak olan mancanalar için 9 karışlık 15.000, 8 karışlık 20.000 ve 7 karışlık fiçı tahtasından 15.000, toplamda 50.000 bin adet fiçı tahtasının 
denize indirilecek gemi ve gemideki asker sayısıyla doğru orantılı olarak, bu iki bölgeden talep edilen yıllık fıçı tahtası miktarının iki üç katına kadar da çıkmıştır. ${ }^{15}$ Temin sırasında fiçı tahtalarının donanma açısından önemi belirtilip, istenilen zamanda, eksiksiz bir şekilde tahtaların İstanbul'a teslimi konusunda mübayaa yapılan bölgenin yöneticilerinden ve tahtaların gemilere yükleneceği iskelelerin bulunduğu bölge (İbril ve Kalas) yöneticilerinden ${ }^{16}$ gerekli hassasiyet ve özenin gösterilmesi istenmiştir. Her ne kadar voyvodalar gerekli olan fıçı tahtalarının temini ve İstanbul'a gönderilmesi konusunda özveriyle çalışmış olsalar da, genellikle devlet tarafından talep edilen miktardan az ${ }^{17}$ ya da parça parça Tersane-i Âmire ve Aynalıkavak Sahilsarayına göndermişlerdir. ${ }^{18}$

Eflak ve Boğdan voyvodalıkları dışında Ahtapolu ${ }^{19}$, Biga ${ }^{20}$, Midilli, Sakız, İzmir, Şile, Kandıra, Varna, Gelibolu ve Lapseki gibi bölgelerden de ihtiyaç halinde gerekli olan çeşitli uzunluktaki fiçı tahtasının temini yoluna gidilmiştir. ${ }^{21}$

Temin sırasında inşa olunacak olan mancana vs. için gerekli olan tahtanın miktarı ve uzunluğu belirtilmiştir. Ağırlıklı olarak 9, 8 ve 7 karışlık ${ }^{22}$ tahtalar inşa sırasında tercih edilmiş olsa da ihtiyaç halinde 4 karıştan 12 karışa kadar uzunluktaki tahtaların mübayaası gerçekleştirilmiştir. ${ }^{23}$ Yapılan alımlar miri fiyat üzerinden olup, miri fiyat piyasa fiyatının (rayiç fiyat) altında olduğundan kimi zaman tahtanın alınacağı kişiler tarafından miri fiyat kabul görmemiştir. Ancak devlet, bu malzemenin donanma açısından önemini belirterek miri fiyattan mübayaayı gerçekleştirmiştir. ${ }^{24}$

temin edilip Tersane-i Âmire’ye gönderilmesi Eflak voyvodasından istenmiştir.

15 BOA. C.BH.28-1327., H.1210 (M.1796) tarihli belgede, donanma gemileri için elzem olan su mancanalarının yapılması için Kalas bölgesinden 8 karışlık 35 bin, 7 karışlık 31 bin ve 6 karışlık 65 bin adet, toplamda 131.000 adet fiçı tahtasının mübayaası planlanılmıştır.

16 BOA. C.BH.24-1135., H.1218 (M.1803) tarihli belgede, Tersane-i Âmire kalyonlarının su mancanaları için gerekli olan 50.000 fiçı tahtasının Eflak voyvodası tarafından hazırlanmasından sonra, İbril nazırına tahtaların naklinin yapılacağı İbril iskelesinin korunması için emir gönderilmiştir.

17 BOA. C.BH.32-1537., H.1215 (M.1800) tarihli belgede, donanma ve kara askerleri için gerekli olan mancanaların yapılması için 90.000 adet tahtanın temin edilip gemilerle İstanbul'a gönderilmesi Eflak voyvodasından istenmiştir. Voyvoda her ne kadar bu işi yapmaya çalışsa da 14.000 tahtadan fazlasını yükleyemediği, bahsi geçen sene zarfında değil sonraki seneye bile istenen miktarın yetişmeyeceği belirtilmiştir. Bu durumun donanmanın göreve çıkamamasına neden olacağı da belirtilmiştir

18 BOA. C.BH.210-9814., H.1215 (M.1800) tarihli belgede, H.1214 ve 1213 senesinde, Boğdan voyvodasından 9 karışlik 40.000, 8 karışlık 32,500 ve 7 karışlık 27.500, toplam 100.000 fiçı tahtası istenmiştir. İstenilen tahtalar parça parça (ceste ceste) gelmiş olup, bir kısmını Tersane-i Âmire’ye bir kısmı da Aynalıkavak sarayına gönderilmiştir. 9 karışlık 10.154, 8 karışlık 25.586 ve 7 karışlık 10.245 toplam 56,254 tahtanın Memiş Efendiye ulaştı̆̆ı, gelen tahtalar için toplam 2249,5 kuruşun seferiye akçesinden ödenmesi istenmiştir

19 BOA. C.BH.265-12234.

20 BOA. C.BH.128-6190.

21 BOA. C.BH.111-5378.

22 Osmanlı Devleti'nde kullanılan uzunluk ve ağırlık ölçülerini görmek için bknz. İsmail Özçelik, Devlet-i Aliyye’nin Taşra Yönetimi, Gazi Kitabevi, Ankara, 2016, s. 104-106.

23 BOA. C.BH.111-5378., H.1204 (M.1790) tarihli belgede, baharda açılacak olan donanma için gerekli olan fiçı ve varillerin tahtası için, Midilli, Sakız, İzmir, Şile, Kandıra, Varna, Gelibolu ve Lapseki iskelelerinde, 4 karıştan 12 karışa kadar ne kadar fıçı ve varil tahtası varsa bunların mübaşirler vasıtasıyla alınması bölge yöneticilerinden istenmiştir.

24 BOA. C.BH.199-9340., H.1198 (M.1784) tarihli belgede, donanma için çok önemli olan mancaların hazırlanmasında kullanılacak olan 7 karış tahtaların İstanbul'da olmadığı bu sebepten, tahtaların Ahtapolu iskelesinden mübayaa olunacağı, ancak oradaki tahtaların da 6 karış olduğu ancak tersane ricalinin bu malzemenin bekletilmeye gelmeyecek kadar önemli olduğunu bildirmesinden 6 karışlık tahtanın miri fiyattan alınıp bir an önce gemilere yüklenip İstanbul'a gönderilmesi istenmiştir. Ancak miri fiyatın 7 karışlık tahta için 5, 6 karış tahta için 4 akçe olmasından tahtaların sahibi miri fiyattan fazla bir para isteyip malın alınmasına engel olmaya çalışmıştır. 
Yapılan alımlarda belirlenen birim ve miri fiyat konusuna gelecek olursak, Eflak ve Boğdan bölgesinden yapılan alımlarda genellikle, 9 karışlık fiçı tahtasının bin tanesine 45 kuruşş, 8 karışlık fiçı tahtasının bin tanesine 40 kuruş ve 7 karışlık fiçı tahtasının bin tanesine 35 kuruş miri mübayaa fiyatı belirlenmiş ${ }^{26}$ olsa da, bazı alımlarda 8 karışlık bin fiçı tahtasına 45 kuruş, 7 karışlık bin fiçı tahtasına 40 kuruş ve 6 karışlık bin fiçı tahtasına 35 kuruş miri mübayaa fiyatı belirlenmiştir. ${ }^{27} \mathrm{Bu}$ rakamlar bize alım sırasında istenilen en uzun ve en kısa tahta için belirli bir tavan ve taban fiyat olduğu düşüncesini vermektedir.

Eflak ve Boğdan dışından yapılan alımlarda ise belirlenen fiyat şu şekildedir. Ahtapolu bölgesinden mübayaa olacak 7 karışlık tahtanın bir tanesine 5 akçe, 6 karışlık olan tahtanın bir tanesine 4 akçe mübayaa fiyat ${ }^{28}$ belirlenmiş olup, mübayaa fiyatı Biga ve havalisi için 8 karışlık fiçı tahtasının bir tanesi için 5 akçe, 7 ve 6 karışlık olanların bir tanesi için 4 akçe üzerinden olmuştur. ${ }^{29}$

Fıçı tahtası dışında mancana, fıçı ve varil inşasında gerekli olan diğer malzemede demir çemberdir. Demir çember kimi zaman İstanbul veya İstanbul'a yakın bölge varilci esnafinda işlenmiş şekilde ${ }^{30}$ alınmış olsa da genellikle ham demir (âhen-i ham ${ }^{31}$ ) şeklinde mübayaası yapılıp, inşa olacak mancana, varil ve fiçının boyutuna göre işlenmiştir. Yapılan mübayaada birim ağırlık olarak kantar (kantar-lodra ${ }^{32}$ ) kullanılmış olup, kaç kantar ham demirinn ${ }^{33}$, kimden, hangi birim fiyattan alındığ 1 , bedelin nereden ödeneceğ $i^{34}$ ve kaç mancana ve fiçının hazırlanmasında kullanılacağı ayrıntılı bir şekilde belirtilmiştir. ${ }^{35}$

25 BOA. C.BH.115-5582., H.1215 (M.1801) tarihli belgede, donanma için lazım olan su mancanaları için, 100 bin fiçı tahtasının 50 bini Eflak, 50 bini Boğdan voyvodalarından belirtilen uzunlukta temin edilip, Kalas ve İbril iskelelerinden, Tersane-i Âmire'ye göndermeleri istenmiştir. Talebe göre fiçı tahtalarının uzunlukları 9, 8 ve 7 karış uzunluğunda olacaktır. 9 karışlık tahtanın bin tanesi 45 kuruştan, 8 karışlık tahtanın bin tanesi 40 kuruştan ve 7 karışlık tahtanın bin tanesi 35 kuruştan mübayaa edilecektir. 9 karışlık 15.000 adet, 8 karışlık 20.000 adet ve 7 karışlık 15.000 tane fiçı tahtasını aynı miktarda iki taraftan da istenmiştir.

26 BOA. C.BH.210-9814., H.1215 (M.1800) tarihli belgede, H.1214 ve 1213 senesinde, Boğdan voyvodasindan istenen 9, 8 ve 7 karışlık fıçı tahtalarının 9 karışlık olanlarının bin tanesi 45, 8 karışlık olanların bin tanesi 40 ve 7 karışlık olanların bin tanesi 35 kuruştan mübayaa edilmiş olup, mübayaa bedeli seferiye akçesinden ödenmiştir.

27 BOA. C.BH.28-1327., H.1210 (M.1796) tarihli belgede, Eflak ve Boğdan’dan mübaaysı yapılacak olan 8 karışlık fiçı tahtasının bin tanesine 45 kuruş, 7 karışık fiçı tahtasının bin tanesine 40 kuruş ve 6 karışık fiçı tahtasının bin tanesine 35 kuruş miri mübayaa fiyatı belirlenmiştir.

28 BOA. C.BH.199-9340.

29 BOA. C.BH.128-6190., H.1212 (M.1798) tarihli belgede, kebir su mancalarının inşası için 8 karışık 17.500, 7 karışlık 15.500 ve 6 karışlık 32.500, toplam da 65.500 meşe fiçı tahtası Biga havalisinden istenmiştir. Fıçı tahtalarının 8 karışlık olanı için tanesi 5 akçe, 7 ve 6 karışlık olan tahtanın tanesi için 4 akçe birim fiyat belirlenmiştir.

30 BOA. C.BH.265-12234., H.1198 (M.1784) tarihli belgede fiçılar için gerekli olan yaklaşık 1300 çemberin Sakarya'da bulunan varilci esnafında olduğu, çemberlerin gönderilmesi için Karasu ayanlarından Mustafa Ağa adlı kişiye emir gönderilmiştir.

31 İdris Bostan, a.g.e., s. 121.

32 Kantar $=56.449 \mathrm{~kg} /$ Lorda=0.564 kg. İ. Özçelik, a.g.e., s.104-106.

33 BOA. C.AS.1184-52827.

34 BOA. C.BH.169-7958., H.1226 (M.1811) tarihli belgede, 290 kantar 75 lodra ağırlında demir çemberin kantarı 25 kuruştan 7268 kuruşa Kivrok adlı zimmiden alınmış olup, bedeli Tersane-i Âmire hazinesinden ödenmiştir

35 BOA. C.BH.238-11045., .1215 (M.1801) tarihli belgede, donanma için duhan gümrük emini Memiş Efendi tarafindan yapılan 2000 mancana ve 4500 su varilinin demir çemberi için 2000 kantar ham demir istenmiş olup, ilk etapta 1500 kantar ham demir, kantarı 13 kuruştan mübayaa edilmiştir. 


\section{Nakliye Meselesi}

Mancana, fiçı ve varil için gerekli olan tahtaların bahsi geçen bölgelerden mübayaasından sonra, inşa için İstanbul'a Tersane-i Âmire ve Aynalıkavak Sahilsarayına gönderilmesi ve daha sonra da inşası tamamlan mancana, fiçı ve varilin ihtiyaç olan yerlere denizyoluyla gönderilmesi gerekmiştir. ${ }^{36}$ Devlet bu iş için ağırlıklı olarak gemi kiralama yoluna gitmiştir. Kiralanan gemiler çoğunlukla Gayrimüslim kaptanlara ${ }^{37}$ ait olsa da Müslüman kaptanlara ait gemiler de taşıma için kiralanmıştır. ${ }^{38}$ Yapılacak kiralamadan önce gönderilecek tahta ya da mancana, fiçı ve varil sayısı belirlenip, kaç geminin bu iş için yeterli olacağı ve taşıma için navlun bedelinin ne kadar olacağı geminin taşıma kapasitesine göre (kile / hamule) hesaplanmıştır. Yapılan hesaplamadan sonra kiralanacak gemilerin kaptanlarıyla mukavele yapılmıştır. Yapılan mukavelede, kiralanan geminin kime ait olduğu, ne kadar zaman için kiralandığ $1^{39}$, geminin yükü hangi limandan alacağı ve nereye teslim edeceği, geminin taşıma kapasitesi ve yüklenecek tahta veya mancana, fiçı ve varil sayısının kaç olduğ ${ }^{40}$ gibi bilgiler ayrıntılı bir şekilde belirtilmiştir. ${ }^{41}$ Yapılan mukavelelerde genellikle belirlenen navlun bedelinin 3'te 2'si peşin olarak, geriye kalan 3'te 1'inin de yüklenen malzemenin eksiksiz ve zamanında tesliminden sonra kaptana ödendiğini görürüz. ${ }^{42}$

36 BOA. C.BH.113-5463., H.1215 (M.1801) tarihli belgede, müttefik İngiltere donanmasına verilen çeşitli mühimmattan başka, 1000 adet demir çemberli su varili de verilmiştir. Çeşitli mühimmat ve su varillerinin nakliyesi için 13.000 kilelik gemi kiralanmış ve navlun için kile başına 15 para verilip toplam bedel 19.500 para, 1 kuruş 40 para hesabıyla 4875 kuruş etmiş̧ir. Bu bedelin 3'te 1'i olan 1625 kuruşu peşin, geri kalan 3250 kuruşta görev bitince ödenmiştir.

37 BOA. C.BH.34-1612., H.1215 (M.1801) tarihli belgede, İskenderiye'ye 100 asker ve su mancanası gönderilmesi için Ahmet Ağa adlı kişinin marifetiyle, Yorgi reis adlı kişinin gemisi 2500 kuruşa kiralanmıştır. Yapılan mukavele gereği paranın 3'te 2'si olan 1666 kuruş peşin, geri kalan 3'te 1'i ise görevin tamamlanmasından sonra verilmiştir.

38 BOA. C.BH.210-9814., H.1215 (M.1800) tarihli belgede, H.1214 ve 1213 senesinde, Boğdan voyvodasından 9 karışlık 40.000, 8 karışlık 32,500 ve 7 karışlık 27.500, toplam 100.000 fiçı tahtası istenmiştir. İstenilen tahtalar parça parça (ceste ceste) gelmiş olup, bir kısmını Tersane-i Âmire'ye bir kısmı da Aynalıkavak sarayına gönderilmiştir. Tahtaların nakliyesi sırasında Müslim ve Gayrimüslim gemi kaptanlarına ait çeşitli türden gemiler kullanılmış olup, hangi kaptanın gemisiyle hangi ay ve günde, hangi uzunlukta kaç tahtanın getirildiği ayrıntılı bir şekilde belirtilmiştir.

39 BOA. C.BH.94-4516., H.1215 (M.1800) tarihli belgede, donanma için yaptırılmış olan demir çemberli 500 adet mancana ve 1000 adet varilin nakliyesi için Yanni reis adlı kaptanın 8000 kile hamulelik ve diğeri Hacı Ahmed reis adlı kaptanın 13.000 kile hamulelik gemileri 3 aylığına kiralanmıştır. Yapılan mukavele gereği gemilerin her 1000 kilesi için 125 kuruş kira bedeli verilecek olup, 8000 kilelik gemi için aylık 1000, 3 aylık 3000 kuruş, 13.000 kilelik gemi için aylık 1625, 3 aylık 4875 kuruş kira bedeli ödenmiştir.

40 BOA. C.BH.27-1269., H.1216 (M.1801) tarihli belgede, İstanbul'dan asker ve mancana nakli için Yusuf Agah Efendi tarafından 2500 kuruşa Yorgaki? adlı zimmi reisin gemisi kiralanmıştır. Yapılan mukavele gereği reise navlun 3'te 2'si olan 1666 kuruş peşin geri kalan 3'te 1'i 833 kuruş ise görevin tamamlanmasından sonra seferiye akçesinden verilecektir. Zimmi reis askerleri İskenderiye'ye indirdiğini ve 83 adet mancanayı da Rodos Mutasarrıfına teslim ettiğini belirterek, geri kalan 833 kuruş ücretini talep etmiş, yapılan hesaplama sonrası 33 kuruş tenzilatla 800 kuruş kaptana ödenmiştir.

41 BOA. C.BH.32-1537., H.1215 (M.1800) tarihli belgede mübayaa olunan 180.000 mancana ve fiçı tahtalarının yarıya yakın kısmını İstanbul'a getirmek için devlet dört gemi kiralamış olup, gemiler, Kalas ve İbril iskelelerinden yükü alıp yola çıkacaklardır. Gemi kaptanlarıyla yapılan anlaşma gereği kile başı 14 paradan nakliye ücreti verilecek olup, ücretin 3'te 2'si peşin geri kalan 3'te 1'i yükün boşaltılmasından sonra verilecektir. Şayet bir tahta bile eksik olursa paranın kesileceği belirtilmiştir. Kiralanan gemilerin taşıma kapasitesi ve yükleyebildikleri tahta sayısı şu şekildedir, Hüseyin reis adlı kaptanın 7000 kile hamuleli gemisine 20.000 tahta, Mustafa reis adlı kaptanın 8000 kilelik gemisine 22.856 tahta, Ahmet reis adlı kaptanın 8000 kilelik gemisine 22.856 tahta, Aşçı Hüseyin reis adlı kaptanın 12.000 kilelik gemisine 34.284 adet tahta yüklenmiştir. Yapılan 40 para 1 kuruş hesabına göre Hüseyin reis 2450 kuruşun 1633 kuruşunu peşin 817 kuruşunu sonra, Mustafa ve Ahmet reis 2800 kuruşun 1866 kuruşunu peşin 934 kuruşunu sonra ve Aşçı Hüseyin reis 4200 kuruşun 2800 kuruşunu peşin 1400 kuruşunu teslimattan sonra alacak olup, teslimattan sonra verilecek nakliye bedeli 4085 kuruştur.

42 BOA. C.BH.38-1790., H.1218 (M.1803) tarihli belgede, Boğdan'dan temin edilmiş olan fiçı tahtalarının kiralanan üç gemiyle 


\section{Mancana Varil ve Fıçı Üretimi}

Mancana, varil ve fiçı imalatından önce ilk olarak eskiyen ve tamire muhtaç olan mancana, varil ve fiçıların tamiri ${ }^{43}$ yapılmak istenmiş olup, yenilenen mancana sayısı ihtiyacı karşılamakta yetersiz kalır ise yeni mancana, varil ve fiçıların imalatı aşamasına geçilmiştir. Bu noktada ihtiyaç dâhilinde İstanbul ve havalisi dışında İzmir, Tekfurdağı, İznikmid, Bandırma gibi bölgelerden yevmiyeleri tersaneden verilmek üzere varilci usta ve amelesi getirtilmiştir. ${ }^{44}$ Üretimde yer alacak usta $^{45}$ ve amelelerin sağlanması ve gerekli olan tahta ve demir gibi malzemelerin iki önemli üretim noktası olan Tersane-î Âmire ve Aynalıkavak Sahilsarayına ulaştırılmasından sonra imalat aşamasına geçilmiştir. Ancak imalata başlanmadan önce, doğrudan kaptan paşa ya da tersane ricali tarafından gerekli olan mancana ve fiçının sayısı, istenen sayının kaç tanesinin büyük ve kaç tanesinin küçük boyutta imal edileceği ve kaç tanesinin demir çemberli olacağı ve ayrıca hangi gelir kaynağından karşılanmak üzere (genellikle Tersane-i Âmire Hazinesi ${ }^{46}$ ) hangi birim fiyattan istenen malzemenin üretileceği imalattan sorumlu olan görevliye bildirilmiştir. ${ }^{47}$ Kimi zaman hangi türden gemiye kaç mancana ve fiçının gerektiği belirtilmişs ${ }^{48}$ olsa da çoğunlukla gemi türü ve sayısı belirtilmeden mancana ve fiçı talep edilmiştir. ${ }^{49}$ Talep edilen rakam denize indirilecek ${ }^{50}$ ya da görevlendirilecek olan asker ve gemi sayısıyla doğru orantıda artmıştır. Özellikle çalışma dönemimiz içerisine giren Napolyon'un Mısır'1 işgali ve yaşanan savaş süresince, gerek Osmanlı donanmasının ${ }^{51}$ gerekse

İbril ve Kalos iskelesinden ve İstanbul'a gönderilmiş olduğu, kaptanlarla yapılan mukavele gereği navlun bedelinin 3'te 2'si peşin geri kalanı ise görev tamamlanınca verileceği belirtilmiştir.

43 BOA. AE. SSLM-III. 269-15567., H.1213 (M.1799) tarihli belgede, tersane emini marifetiyle mancana ve varil tamir eden 6 nefere günlük 71 akçeden 426 akçe verilmiş olup, 160 gün için toplam 68.160 akçe ödenmiştir.

44 BOA. C.BH.104-5042., H.1244 (M.1829) tarihli belgede, Galata, Eyüp ve Üsküdar'da 67 varilci esnafının kadimi miri fiyattan donanma kalyonları için gerekli olan mancana ve varilleri hazırladıkları ancak, üretimin ve amele sayısının yetersiz olduğu belirtilip, H.1242 senesinde Tekfurdağı, Kapıdağı, İznikmid, Bandırma, Gemlik, Paşalimanı, Darıca, Kartal, Tuzla, Büyükçekmece gibi yerlerden toplam 72 amele gönderildiği, yine bu yerlerden varilci amelesi istendiği ancak bahsi geçen bölgelerin amele göndermeye kudretlerinin kalmadığı, İzmir'de 25 gediği bulunan varilci esnafından, yevmiyeleri tersaneden verilmek üzere 20 varilci amelesi İzmir Muhafızı Hüseyin Paşa'dan istenmiştir

45 BOA. C.BH.44-2082., H.1225 (M.1810) tarihli belgede, mancana çemberinin de bulunduğu, seren, 1rgat vs. gibi gemi parçalarının demirlerinin Hasköy'de demircibaşı Kigork usta adlı zimminin marifetiyle yapılmış olup, toplam bedel 2145 kuruş olup bu rakam tersane hazinesinden ödenmiştir.

46 Donanmanın harcamaları İrad-1 Cedid Hazinesi kurulana kadar Hazine-i Âmire'den karşılanmıştır. İrad-1 Cedid Hazinesi kurulduktan sonra harcamalar bu hazineden karşılmış olsa da harcamaların büyük bir kısmı 1805 tarihinde kurulacak olan Tersane-i Âmire Hazinesinden karşılanmıştır. Yavuz Cezar, Osmanlı Maliyesinde Bunalım ve Değişim Dönemi (XVIII. yy dan Tanzimat'a Mali Tarih), Alan Yayıncılı, İstanbul, 1986, s. 210-211.

47 BOA. C.BH.174-8177., H.1223 (M.1808) tarihli belgede, donanma için adedi 390 akçeden 418 kebir (büyük) mancana, adedi 240 akçeden 10 sagir (küçük) mancana ve 360 akçeden 70 fiçı için toplam, 190.620 akçe 1 kuruş 120 akçe hesabıyla 1588 kuruş tersane hazinesinden ödenmiştir. / BOA. C.BH.177-8329.

48 BOA. C.BH.20-979., H.1215 (M.1801) tarihli belgede, 5000-6000 kara askerini götürmek için İstanbul'da kalan 4 kalyondan her biri için 350 ve 3 firkateynin her biri için 150 mancananın imal edilmesi Memiş Efendiden istenmiştir.

49 BOA. C.BH.101-4855., H.1237 (M.1821) tarihli belgede, donanma gemileri için yaptırılan 525 mancana ve 449 varil için toplam olarak 1426,5 kuruş Tersane-i Âmire hazinesinden ödenmiştir. 525 mancananın 301 tanesi büyük olup tanesi 130 paradan, 224 tanesi küçük olup tanesi 40 paradan, varilin tanesi ise 20 paradan alınmıştır.

50 Osmanlı Devleti donanmadaki gemi sayısı bakımından Avrupa'da İngiltere, Fransa ve İspanya'nın ardından dördüncü sırada yer almaktadır. 1791-1800 yıllar arasında İngiltere 90 ve Fransa 98 kalyon ve firkateyn inşa etmiş olup bu devletleri 56 gemi inşasıyla Osmanlı Devleti takip etmiştir. Daniel Panzac, Osmanlı Donanması (1572-1923), (Çev. Ahmet Maden-Sertaç Canpolat), İş Kültür Yayınları, İstanbul, 2018, s.239.

51 BOA. HAT.157-6572., H.1215 (M.1800) tarihli belgede, İskenderiye önlerinde olan donanma gemileri için gerekli olan 500 
müttefik İngiliz donanmasının mancana ve varil ihtiyacının ${ }^{52}$ karşılanması için yoğun bir üretim faaliyetine girişilmiştir.

Bu noktada karşımıza sıklıkla Dîvân-ı Hümâyun haceganlarından ve aynı zamanda Duhan (Tütün) Gümrük Eminliği de üzerinde olan Memiş Efendi çıkmaktadır. Memiş Efendi özellikle Napolyon savaşları sırasında donanmanın ihtiyacı olan binlerce mancana, fiçı, varil ve gerdelin imalatında kilit rol oynamış ve binlerce mancana, fiçı, varil ve gerdelin hazırlanmasını sağlamıştır. Arşiv belgelerinden takip edebildiğimiz ölçüde ve çalışma dönemimiz içerisinde, Memiş Efendi'nin ilk olarak beş bin adet demir çemberli mancana inşasını üzerine aldığı, ancak beş bin adet mancananın üretimi devam ederken, Mısır'a gönderilecek olan kara askerleri için H.1215 (M.1801) senesinde iki bin mancananın daha istendiğini görürüz. Memiş Efendi üzerinde olan beş bin demir çemberli mancanın imalatı bittikten sonra ancak istenen iki bin adet mancanayı imal edeceğini belirtmiş̧ ${ }^{33}$ olsa da yine aynı tarih içerisinde kendisinden dört bin beş yüz adet demir çemberli mancanın üretilmesi istenmiştir. Memiş Efendi üzerinde beş bin adet mancanın üretimi olduğunu yine belirtip, talep edilen dört bin beş yüz mancanın imalatının ertelenmesini istemiştir. ${ }^{54}$ Belgelerden takip edebildiğimiz noktada, Memiş Efendi'nin beş bin adet demir çemberli kebir mancananın inşasını tamamlayıp sonradan istenilen iki bin adet mancananın bin tanesini de demir çemberli yapıp inşasını bitirdiğini, geriye kalan bin tanenin ve daha önceden istenen ancak Memiş Efendi'nin ertelenmesini talep ettiği dört bin beş yüz adet mancananın da demir çemberli olması Kaptan-1 Derya Hüseyin Paşa tarafından istenmiş olup, Memiş Efendi dört bin beş yüz mancanın inşasının kendi üzerinde olmadığını belirtmiştir. ${ }^{55}$ Bahsi geçen sene içerisinde Memiş Efendi talep edilen iki bin adet mancana inşasını da tamamlamış olup, yine kendisinden iki bin adet mancananın inşası istenmiştir. ${ }^{56}$ Daha sonraki birkaç y1l içerisinde Memiş Efendi’nin önceki yıllarda yapmış olduğu başarılı imalat faaliyetleri Kaptan-1 Derya tarafından belirtilip kendisinden yine mancana yapması emredilmiştir. ${ }^{57}$ H.1218 (M.1803) tarihli belgede, Aynalıkavak Sahilsarayı bölgesin-

mancana ve 1000 varilin doldurup gönderilmesi için iki adet gemimin tüccardan kiralanması gerekmiştir

52 BOA. C.BH.113-5463., H.1215 (M.1801) tarihli belgede, müttefik İngiltere donanmasına verilen çeşitli mühimmattan başka, 1000 adet demir çemberli su varili de verilmiştir.

53 BOA. C.BH.20-979., H.1215 (M.1801) tarihli belgede toplam 2000 demir çemberli mancananın imal edilmesi Memiş Efendi'den istenmiştir. Memiş Efendi bunu ancak üzerinde olan 5000 demir çemberli mancanayı yaptıktan sonra imal edebileceğini belirtmiştir.

54 BOA. C.BH.47-2211., H.1215 (M.1801) tarihli belgede, Divan-1 Hümayun haceganlarından ve duhan gümrük emini Memiş Efendi'nin marifetiyle 4500 varilin inşası ve demir çemberlerinin yapılması istenmiştir. Ancak Memiş Efendi'nin tersanede işlerin yoğunluğunda bahsederek 5000 adet su mancanasın yapılma işinin de kendisinde olduğunu belirterek, yapılacak işin ertelenmesini istemiştir.

55 BOA. C.BH.60-2861., H.1215 (M.1801) tarihli belgede, Memiş Efendi'nin sorumluluğunda olan ve İskenderiye’ye gidecek olan donanma için inşa olunan 5000 adet demir çemberli kebir mancanadan başka 2000 adet daha mancananın imal edildiği bunların 1000 tanesinin demir, 1000 tanesinin de çubuk çemberli olduğu, demir çemberli olanların teslim edildiği ancak geri kalan 1000 tane çubuklunun ve Tersane-i Âmire'de inşa olunan 4500 su varilinin de demir çemberli üretilmesi Kaptan-1 Derya Hüseyin Paşa tarafından istenmiştir. Ancak 4500 varilin sorumluluğunun kendisinde olmadığını da ifade etmiştir.

56 BOA. C.BH.88-4215., H.1215 (M.1801) tarihli belgede, duhan gümrük emini olan Memiş Efendi marifetiyle, Misır’a gönderilecek olan kara askerleri için öncesinden 2000 mancana yaptırdığı ancak bu miktardan başka 2000 mancanaya daha ihtiyaç olduğu belirtilmiştir.

57 BOA. C.BH.89-4295., H.1217 (M.1803) tarihli belgede Memiş Efendi’nin donanma kalyonları için yaptırdığı su mancanalarından başka Kaptanı-1 Derya’nın isteği doğrultusunda Donanma-yı Hümâyun ve kara askerleri H.1215 senesinde 2000 demir çemberli mancana yaptırmış olduğu belirtilip, yine Memiş Efendi'den 2000 varilin yapılması istenmiştir. / BOA. C.BH.198-9276., H.1219 (M.1804) tarihli belgede, Aynalıkavak Sahilsarayı bölgesinde mancana inşasına görevlendirilmiş olan Memiş Efendi, 4013 adet mancana, 230 adet varil, 235 adet gerdel ve 1 adet tulumbanın yapımında kullanılma için alınan ham 
de Memiş Efendi vasıtasıyla H.1215 (M.1800) Rebiulevvel başlangıcından, H. 1217 (M.1803) Ramazan sonuna kadar geçen yaklaşık olarak iki buçuk üç senelik süre zarfında 7305 demir çemberli mancana, 7500 varil ve 1000 adet gerdelin imal edildiği belirtilmiştir. ${ }^{58}$

\section{Gemide Bulunan Askerlerin Su İhtiyacının Karşılanması}

Donanmaya ait gemilerle bulunan veya bir yerden bir yere günler boyunca süren deniz yolculuğuyla nakledilen askerlerin deniz üzerindeyken içecekleri suyun hazır edilmesi, devletin üzerinde önemle durduğu konuların başında gelmiştir. Genellikle donanmaya ait gemilerde bulunan askerlerin su ihtiyacı denildiğinde akla ilk olarak donanmanın muharip gücü leventler ${ }^{59}$ gelmiş olsa da devletin kara ordusuna bağlı askerler de donanmaya ait gemilerde yer almıştır. Özellikle kara askerlerinin cepheye ya da kale muhafazası ${ }^{60}$ gibi çeşitli görevlerle bir yerden bir yere gönderilmesinde deniz yolu sıklıkla tercih edilmiştir. Bu sebepten askerlerin deniz üzerinde günlerce geçen yolculukları sırasında içecekleri sular için gemilere, yola çıkmadan dolu ya da boş mancana, varil veya fiçının verilmesi varilciler kethüdasından istenmiştir. ${ }^{61}$ Belgelerde, gemide bulunan askerlerin hangi bölgeden nereye ulaştırılacağı belirtilmiş olup ağırlıklı olarak liman bölgelerine askerler gemiyle gönderilmiş olsa da kimi zaman doğrudan deniz ile bağlantısı olmayan bölgelere de askerler deniz yoluyla gönderilmiştir. ${ }^{62}$ Şüphesiz böyle durumlarda bölgeye en yakın limanda askerler indirilip yolun geri kalan kısmını ana güzergâh üzerinde devam etmişlerdir.

Donanmaya ait gemilerle nakilleri sağlanan askerlerin ordunun hangi kısmından ${ }^{63}$ ve kaç orta $^{64}$ veya nefer oldukları belirtilmiştir. ${ }^{65}$ Gönderilecek olan askerin sayısıyla birlikte kaç askere veya

demirin 19.876 kuruş olduğu, bundan başka amele ücreti vs. gibi harcamalar için 40.592 kuruş harcanmış olup, toplam 60.468 kuruş harcanmıştır. Tersane mahzeninden veya mübayaa yoluyla alınıp gönderilmiş olan 8438 adet tahtanın daha sonra inşa olunacak 2000 varil için kullanılması istenmiştir.

58 BOA. C.BH.131-6343. Memiş Efendi'de 3301 kantar 10 vukkiye demir ve 77.218 fiçı tahtasının kaldığ 1 , bundan sonra yapılacak mancana, varil ve gerdellerin bu malzemeden yapılması istenmiştir.

59 BOA. C.BH.7-322., H.1215 (M.1800) tarihli belgede, donanmanın, Napolyon'un Mısır'ı işgalinden sonra Mısır'a gönderildiği ve hala İskenderiye önlerinde olduğu, bu sebeple donanmada bulunan leventlerinin içecekleri sular için 100 mancananın doldurulup gönderilmesi Kıbrıs muhassılından istenmiştir. Mancanaların H.1215 Muharrem 19’unda yüklenip bir iki gün içerisinde donanmaya ulaştırılması planlanmıştır.

60 BOA. C.AS.1053-46282., H.1201 (M.1787) tarihli belgede, Özi Kalesi muhafazasına gönderilecek olan 1000 nefer yamağın gemilerde içeceği su için tanesi 300 akçeden 10 mancana ve tanesi 70 akçeden 100 varil varilciler kethüdası tarafindan teslim edilmiştir. Alınan mancanalar toplam bedeli 3000 akçe, varillerin bedeli 7000 akçe, toplamda ise 10.000 akçe olan bedel, 1 kuruş 120 akçe hesabıyla 83 kuruşa denk gelmiştir

61 BOA. AE.SABH-I. 305-20455., H.1198 (M.1784) tarihli belgede, Mora ve Bosna’ya gidecek olan süratçilere ve ocak mübaşirlerine gemide içecekleri sular (meşrubat) için 2 adet mancana ve 2 adet varilin verilmesi varilciler kethüdasından istenmiştir. Yapılan alım için 8,5 kuruş ödenmiştir.

62 BOA. C.AS.946-41065., H.1230 (M.1814) tarihli belgede, İstanbul'dan Diyarbakır'a deniz yoluyla gönderilen topçu ve arabacıların gemide içecekleri sular için tanesi 16 kuruştan 2 mancana ve tanesi 4 kuruştan 3 adet varil alınmıştır. Topçular için 1 mancana ve 2 varil, arabacılar için 1 mancana ve 1 varil verilmiştir.

63 BOA. C.AS.385-15899., H.1221 (M.1807) tarihli belgede, Bahr-i Sefid boğazından (Çanakkele Boğazı) gemilerle geçecek olan toplam 360 topçular ve tüfekçilerin neferinin gemide içecekleri su için 4 mancana ve 8 varil verilmiştir.

64 BOA. C.AS.85-3941., H.1197 (M.1783) tarihli belgede, İsmail tarafına gemilerle gönderilecek olan bir cebeci ortasının gemilerde içecekleri su için 4 adet mancana ve 20 adet varil verilmiştir. Mancaların tanesi 160 paradan 640 paraya, varillerin tanesi ise 15 paradan 300 paraya alınmış olup, toplam 940 para, 1 kuruş 40 para hesabıyla 23,5 kuruş ödenmiştir.

65 BOA. C.BH.169-7993., H.1200 (M.1786) tarihli belgede, 100 nefer süratçinin (sürat topçuları) kalyonda içecekleri su için 3 adet mancana ve 7 adet varilin verilmesi varilciler kethüdasından istenmiştir. Mancanın adeti 160, varilin adedi 15 paradan alınmış olup, toplam bedel 585 paraya denk gelip, 1 kuruş 40 para hesabıyla 14,5 kuruş ödenmiştir. 
ortaya, kaçar adet mancana, varil ve fiçının hangi birim fiyat üzerinden ${ }^{66}$, kimin marifetiyle verildiği belirtilmiştir. ${ }^{67}$ Şayet gemilerle nakledilecek asker sayısı fazla ise hazırlanacak olan mancana, fiçı ve varilin sayısı da o oranda artmıştır. Buna örnek olarak, Akdeniz'de (Bahr-i Sefid) bulunan kaptan paşanın maiyetine katılmak üzere İstanbul' dan dört kalyon ve üç firkateynle hareket edecek olan 5000 - 6000 civarında askerin gemide içecekleri su için her kalyona 350 ve her firkateyne 150 ve ihtiyaten 150 toplamda ise 2000 mancananın hazırlanmasını gösterebiliriz. ${ }^{68}$

Mancana, varil ve fiçı bedellerinin ödenmesi konusuna gelecek olursak ödemeler sırasında sabit bir birim fiyat ve para birimi olmamıştır. Temin sırasında kimi zaman para, kimi zaman da akçe birim fiyat üzerinden mancana, varil ve fiçının temini sağlanmıştır. Ödemeler sırasında 1 kuruş 120 akçe $^{69}$ ve 1 kuruş 40 para hesab1 üzerinden ${ }^{70}$ hesap yapılıp toplam miktar kuruş olarak belirlendikten sonra bir miktar da tenzilata gidilerek gerekli ödeme gerçekleştirilmiştir.

\section{Sonuç}

Döneminin önemli deniz gücüne sahip devletlerinden biri olan Osmanlı Devleti'nde çeşitli tür ve ebatta gemi mevcuttu. Bu gemilerin inşasından denize indirilip seyrüsefer devamlılığının sağlıklı bir şekilde devamının sağlanabilmesi için bazı malzemelerin temini ve üretilmesi kaçınılmaz hal almıştır. Bu noktada donanmaya ait gemiler içerisinde yer alan askerlerin içecekleri su için çeşitli tür ve ebattaki mancana, fıçı ve varil adı verilen su kaplarının temini ve inşası meselesinin sağlıklı bir şekilde halledilmesi gerekmiştir. Öncelikli olarak devlet görevde olan ya da inşası tamamlanıp denize indirilecek gemi sayısını belirleyip, bu gemiler için kaç adet hangi türden su kabının gerektiğinin tespitini yapmıştır. Bu noktadan sonra, güvenilir ve varlık sahibi bir devlet adamı inşa faaliyetinden sorumlu olmuştur. Şayet seçilen kişi görevi yerine getirme konusunda azimli ve başarılıysa uzunca bir süre, görev kişinin üstünde kalmıştır.

Sorumlu olan kişinin belirlenmesiyle birlikte ihtiyaç olan mancana, fiçı ve varilin inşasında kullanılacak malzemeler iki ana üretim merkezi olan Tersane-i Âmire ve Aynalıkavak Sahilsarayına gönderilmiştir. Gönderilen malzemelerin başında fiçı tahtası ve ham demir gelmiştir. Çeşitli tür ve ebatta kesilmiş olan fiçı tahtaları geniş Osmanlı coğrafyası içerisinde kolaylıkla temin edilmiş o-

66 BOA. C.AS.1185-52894., H.1198 (M.1784) tarihli belgede, Anapa’ya gemilerle gidecek olan 200 yeniçerinin gemide içeceği sular için tanesi 300 akçeden 4 adet mancana ve tanesi 70 akçeden 20 varilin verilmesi varilciler kethüdasından istenmiştir. İstenilen mancana ve varillerin toplam bedeli 2600 akçe, 1 kuruş 120 akçe hesabiyla 21,5 kuruş etmesine karşın 6,5 kuruş tenzilata gidilip 15 kuruş ödenmiştir.

67 BOA. C.AS.807-34257., H.1216 (M.1802) tarihli belgede, Mısır’a gönderilecek askerler için Yusuf Agah Efendi’nin marifetiyle bir gemi kiralanmış; gemide bulunan askerler için 5 mancana, 1210 adet varil ve 220 gerdel alınmıştır. Bunun dışında gemide bulunan askerler için Tersane-i Âmire liman reisi marifetiyle 1047 varil, 855 gerdel 3 mancana ve 2 adet tulumba temin edilmiştir.

68 BOA. C.BH.20-979., H.1215 (M.1801) tarihli belgede, H.1214 senesinde Cabbarzade kapukethüdası Mustafa Bey ve Memiş Efendi adlı kişilerin imal ettikleri mancanaların hala Bahr-i Sefid'de görevde olan kaptan paşa maiyetindeki donanmaya verildiği, yaklaşık olarak 5000-6000 kara askerini götürmek için İstanbul'da kalan 4 kalyondan her biri için 350 ve 3 firkateynin her biri için 150 toplamda 1850 ise mancana gerektiği buna ek olarak ihtiyaten 150 mancananın daha eklenerek toplam 2000 demir çemberli mancananın imal edilmesi Memiş Efendi'den istenmiş olup, Memiş Efendi bunu ancak üzerinde daha önceden olan 5000 demir çemberli mancanayı yaptıktan sonra imal edebileceğini belirtmiştir.

69 BOA. C.AS.1185-52894.

70 BOA. C.AS.1141-50704., H.1201 (M.1787) tarihli belgede, İsmail bölgesine beş topçu ortas1 gemilerle gönderilmiştir. Bu askerlerin gemilerde içecekleri su için her ortaya tanesi 160 paradan 3 mancana ve tanesi 15 paradan 7 varil olmak üzere toplam 15 mancana ve 35 varil, 2925 paraya, 1 kuruş 40 para hesabına göre 73 kuruşa varilciler kethüdası tarafından teslim edilmiştir. 
lup, ağırlıklı olarak Eflak ve Boğdan bölgeleri devletin ana fiçı tahtası sağladığı merkez konumuna gelmiştir. Bu bölgelerden voyvodalar vasıtasıyla mübayaası gerçekleştirilen fiçı tahtaları kiralanan gemilerle üretim merkezi olan Tersane-i Âmire ve Aynalıkavak Sahilsarayına nakledilmiştir. Genellikle fıçı tahtaları gemilere yüklenmeden önce gönderilecek fiçı tahtası için gerekli olan geminin seçimi yapılıp, kaptanlarıyla mukavele yapılmıştır. Yapılan mukavelelere göre belirlenen navlun bedelinin 3'te 2'si tahtanın gemilere yüklenmesinden sonra, geri kalan 3'te 1'i ise yükün boşaltılmasından sonra ödenmiştir. Bu sayede olası bir malzeme kaybının önüne geçilmeye çalış1lmiştır.

Genel olarak baktığımızda fıçı tahtasının temini ve nakliyesi konusunda büyük bir sıkıntı yaşanmazken, yaşanan sıkıntılar genellikle Eflak ve Boğdan bölgelerinden talep edilen elli binin üzerinde fiçı tahtasının istenilen zamanda istenilen miktarda gönderilememesinden ya da diğer bölgelerden yapılan alımlarda devletin belirlemiş olduğu miri fiyat ve rayiç fiyat arasındaki farktan kaynaklanmıştır. Ancak devlet fiçı tahtasının donanma açısından önemini belirtip, miri fiyat politikasından taviz vermeden istenilen miktarda tahtayı miri fiyattan mübayaa etmiştir.

Devletin su kaplarının inşasında kullandığı malzemeleri kendi sınırları içerisinde temin etmesi yüklü miktarda paranın ülke içerisinde kalmasını sağlamış ve stratejik açıdan devletin elini oldukça güçlendirmiştir. Kısacası bu noktada devletin, dışa bağlı kalmadan rahatlıkla kendi kendisine yetebilecek seviyede olduğunu ifade edebiliriz.

\section{KAYNAKÇA}

\section{I- ARŞIV BELGELERI}

TÜRKIYYE CUMHURIYETİ CUMHURBAŞKANLIĞI DEVLET ARŞIVLERİ BAŞBAKANLIĞI OSMANLI ARŞIVİ (BOA.)

\section{ALİ EMIRI:}

Sultan I. Abdülhamid (AE.SABH-I): 305-20455.

Sultan III. Selim (AE.SSLM-III): 269-15567.

\section{CEVDET:}

Askeriye (C.AS): 85-3941, 385-15899, 807-34257, 946-41065, 1053-46282, 1141-50704, 1184-52827, 1185-52894.

Bahriye (C.BH): 7-322, 20-979, 24-1135, 27-1269, 28-1327, 32-1537, 34-1612, 38-1790, 44-2082, 47-2211, 60-2861, 88-4215, 89-4295, 94-4516, 101-4855, 104-5042, 111-5378, $113-$ 5463, 115-5582, 128-6190, 131-6343, 169-7958, 169-7993, 174-8177, 177-8329, 198-9276, 1999340, 210-9814, 238-11045, 265-12234, 271-12501.

\section{HATT-I HÜMAYUN (HAT):}

157-6572.

\section{II-ARAŞTIRMA ESERLER}

AGOSTON, Gabor, Osmanlı'da Ateşli Silahlar ve Askeri Devrim Tartışmaları, (Yay. Haz. Kahraman Şakul), İş Kültür Yayınları, İstanbul, 2017.

AGOSTON, Gabor, Osmanlı'da Strateji ve Askerî Güç, (Çev. M. Fatih Çalışır) Timaş Yayınları, İstanbul, 2015. 
AKSAN, H. Virgina, Kuşatılmış Bir İmparatorluk Osmanlı Harpleri 1700-1870, (Çev. Gül Çağalı Güven), Türkiye İş Bankası Kültür Yayınları, İstanbul, 2011

ANTONOV, Aleksandır, "Bulgar Topraklarında Kurulan Menzil Sisteminin Organizasyonu (XVI-XVIII. Yüzyıllar)”, Türkler, C.10, (Edt. Hasan Celal Güzel), Yeni Türkiye Yayınları, Ankara, 2002.

BOSTAN, İdris, Osmanlı Bahriye Teşkilâtı: XVII. Yüzyılda Tersâne-i Âmire, T.T.K., Ankara, 2003.

CEZAR, Yavuz, Osmanlı Maliyesinde Bunalım ve Değişim Dönemi (XVIII. yy dan Tanzimat'a Mali Tarih), Alan Yayınc1lı, İstanbul, 1986.

CHASE, Kenneth, Ateşli Silahlar Tarihi, (Çev. Füsun Tayanç), Türkiye İş Bankası Kültür Yayınları, İstanbul, 2008.

FAROQHI, Suraiya, "İktisat Tarihi”, Türkiye Tarihi, C.2, (Yay. Yön. Sina Akşin), Cem Yayınları, İstanbul, 1997.

İşBILLIR, Ömer, "Osmanlı Ordularının İaşe ve İkmali: I. Ahmed Devri İran Seferleri Örneği ", Türkler, C.10, (Edt. Hasan Celal Güzel) Yeni Türkiye Yayınları, Ankara 2002.

ÖZÇELIK, İsmail, Devlet-i Aliyye'nin Taşra Yönetimi, Gazi Kitabevi, Ankara, 2016.

PAKALIN, Mehmet Zeki, Osmanlı Tarih ve Deyimler Sözlüğü, C.2, Milli Eğitim Basımevi, İstanbul, 1983.

PANZAC, Daniel, Osmanlı Donanması (1572-1923), (Çev. Ahmet Maden-Sertaç Canpolat), İş Kültür Yayınları, İstanbul, 2018.

TABAKOĞLU, Ahmet, Osmanlı Mali Tarihi, Dergah Yayınları, İstanbul, 2016.

UZUNÇARŞILI, İsmail Hakkı, Osmanı Devleti'nin Merkez ve Bahriye Teşkilâtı, T.T.K., Ankara, 1988.

YILDIZ, Gültekin, "Kara Kuvvetleri", Osmanlı Askeri Tarihi Kara, Deniz ve Hava Kuvvetleri 1792-1918, (Edt. Gültekin Yıldız), Timaş Yayınları, İstanbul, 2017. 


\section{EKLER}

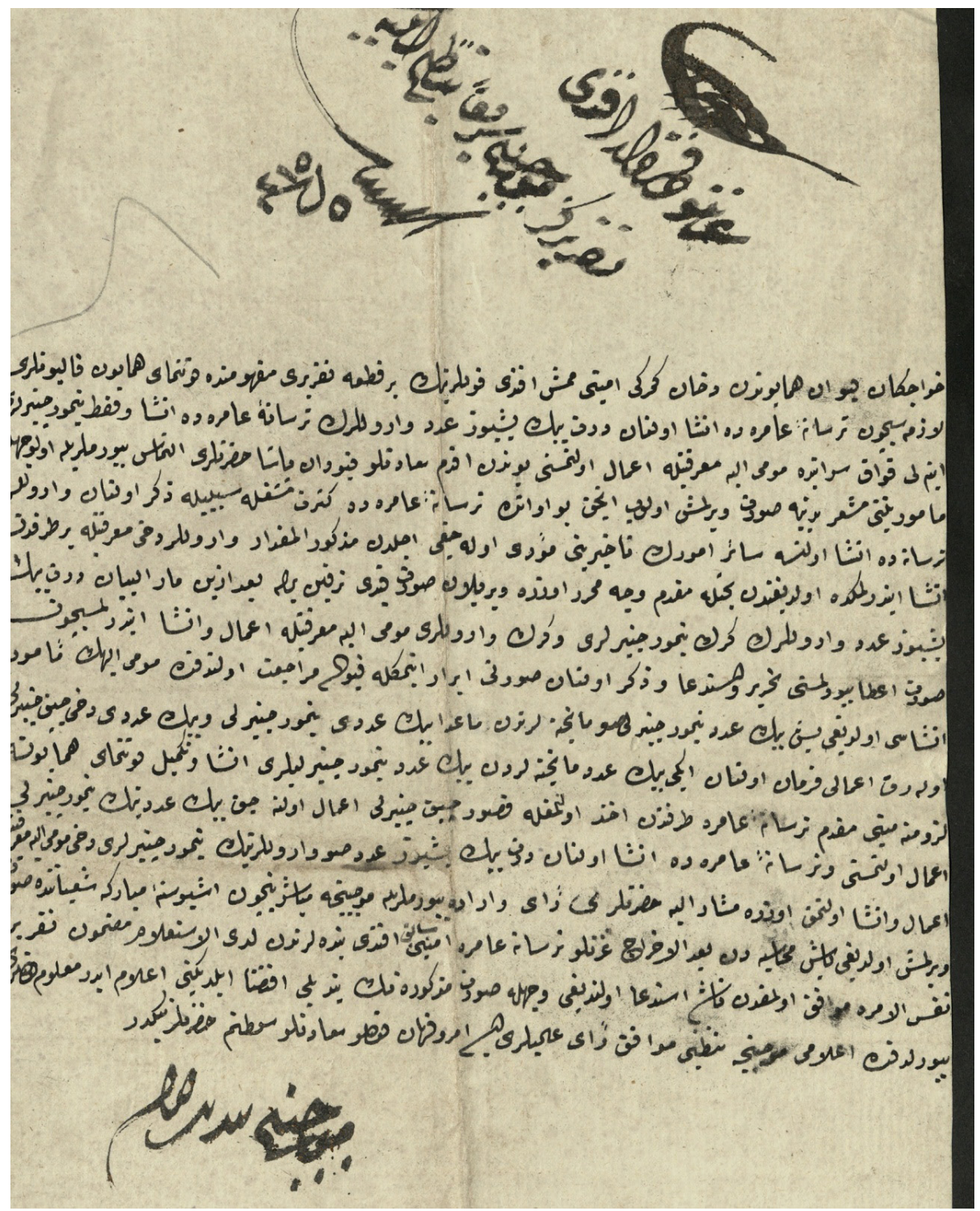

Ek-1. Memiş Efendi'nin marifetiyle imal edilen mancanalara dair (BOA. C.BH.47-2211). 


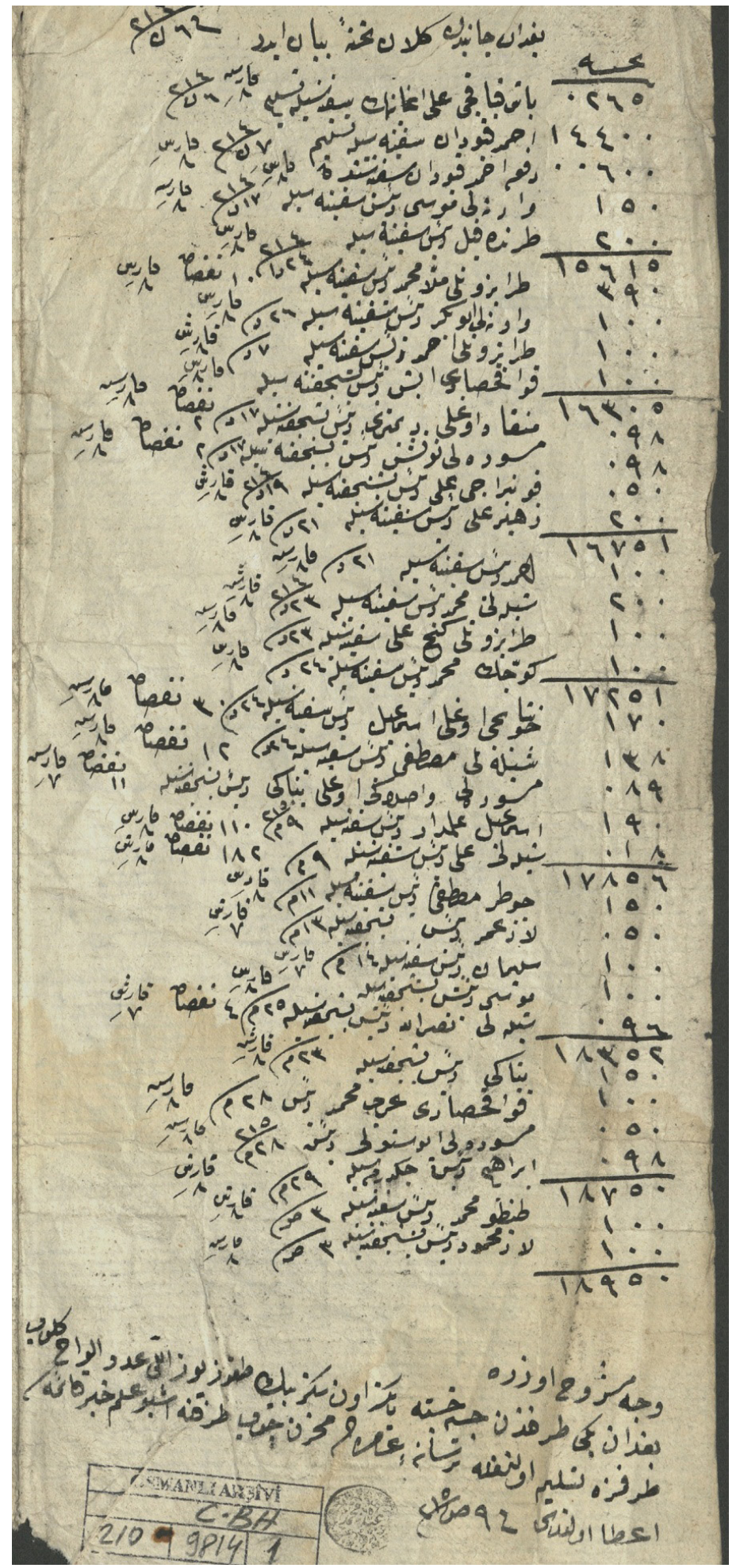

Ek-2. Boğdan'dan mübayaası gerçekleştirilen ve kiralanan gemilerle İstanbul'a gönderilen çeşitli uzunluktaki fiçı tahtalarına dair (BOA. C.BH.21-9814). 